\title{
How do orthopaedic surgeons inform their patients before knee arthroplasty surgery? A cross-sectional study
}

\author{
Aamir Mahdi ${ }^{1,2^{*}}$ (D), Maria Hälleberg Nyman ${ }^{3}$ and Per Wretenberg ${ }^{1,2}$
}

\begin{abstract}
Background: Total knee arthroplasty (TKA) is a successful and common procedure. However, 6-28\% of patients are dissatisfied postoperatively. The provision of preoperative patient information, inquiring about patients' expectations, and taking a psychiatric history are essential parts of both preoperative evaluation and postoperative outcome. The aim of this study was to investigate how orthopaedic knee surgeons in Sweden inform their patients before surgery.
\end{abstract}

Methods: A questionnaire was distributed to all knee surgeons performing TKA in Sweden. Responses were received from 60 of the 65 orthopaedic departments performing TKA in Sweden (92\%), covering 219 of the approximately 311 knee surgeons at the 65 departments (70\%). The answers were analysed with descriptive statistics. A content analysis of the surgeons' opinions was also performed using a thematic method.

Results: In terms of information provision, $58 \%$ of the surgeons always gave written information while $92 \%$ informed orally. Only 44\% always asked about the patient's expectations, and only 42\% always informed patients about the 20\% dissatisfaction rate after TKA. Additionally, 24\% never operated on mild indication of arthrosis, 20\% always took a psychiatric history, and half never or seldom consulted a psychiatrist. However, all the knee surgeons believed in a psychiatric impact on TKA outcome. Qualitative analysis revealed five common causes of patient dissatisfaction, which in descending frequency were: patients' expectations, choice of patients to operate on, surgical factors, combinations of factors, and insufficient information provision to patients.

Conclusions: Knee surgeons in Sweden have considerable awareness of the importance of preoperative patient information, the impact of patient expectations, and psychiatric illness. However, they need to improve their preoperative routines when it comes to providing written information, asking about the patient's expectations, and psychiatric assessment.

Keywords: Expectation, Postoperative outcome, Preoperative information, Psychiatric history, TKA

\section{Background}

Total knee arthroplasty (TKA) is a common procedure with generally good results. By 2030, the annual number of TKA operations performed in the USA is expected to have reached 3.48 million, an increase of $673 \%$ from the figures for 2005 [1]. The most recent annual report from the Swedish knee arthroplasty

\footnotetext{
* Correspondence: aamir.mahdi@oru.se

${ }^{1}$ Department of Orthopaedics, Örebro County, Sweden

${ }^{2}$ Faculty of Medicine and Health, School of Medical Sciences, Örebro

University, Örebro, Sweden

Full list of author information is available at the end of the article
}

register shows a similar trend, with an increase from 70 to 140 TKA procedures per 100,000 inhabitants between 2000 and 2015 [2]. However, despite advances in design and technique, there are still patients who are not satisfied after this procedure. Previous studies have shown many reasons for dissatisfaction [3-24], for example early- and late postoperative complications, unfulfilled expectations, anxiety and depression. Further, earlier studies have shown a correlation between dissatisfaction and mechanical $[5,14]$ and/or psychological factors [16]. In Sweden, the risk of

(c) The Author(s). 2018 Open Access This article is distributed under the terms of the Creative Commons Attribution 4.0 International License (http://creativecommons.org/licenses/by/4.0/), which permits unrestricted use, distribution, and reproduction in any medium, provided you give appropriate credit to the original author(s) and the source, provide a link to the Creative Commons license, and indicate if changes were made. The Creative Commons Public Domain Dedication waiver (http://creativecommons.org/publicdomain/zero/1.0/) applies to the data made available in this article, unless otherwise stated. 
dissatisfaction after knee arthroplasty is about $8 \%$ in the absence of complications [22, 23].

Patient dissatisfaction contradicts the aim of TKA surgery in improving patient's quality of life [10, 25-27]. It implies a burden for both patients and health care professionals [28-32]. Most of the previous studies conducted to address the problem of dissatisfaction and to analyse the preventable factors in order to decrease this rate. $[6,10,12,15,25,26,33-38]$

Orthopaedic surgeons may have different ways of dealing with how patients are informed preoperatively, as well as different opinions about the importance of preoperative information in relation to postoperative outcome. Preoperative information includes a general written and verbal information, patient expectations, information about the 20\%-non-satisfaction's rate and psychiatric history. A previous study showed a discordance between surgeon and patient satisfaction after knee arthroplasty surgery [39]. Moreover, a qualitative study by Conrades et al. showed a relationship between how the TKA patient was informed preoperatively and how much they trusted the department [40].

When it comes to reducing the risk for patient dissatisfaction, we know the importance of a qualified preoperative information according to the patient's needs and selection of the right patient for surgery $[12,18,40-44]$, but we do not know the extent of the problem in Sweden in terms of the surgeon's attitude to the information, patient selection, and the surgeon's opinion about patient dissatisfaction. There are few studies which describe orthopaedic surgeons' attitudes toward giving information to patients. The aim of this study was therefore to investigate how TKA surgeons in Sweden inform their patients preoperatively, and what kind of information they give. This will lead to strategies and possibly changing protocols to improve the knee surgeon's attitude in preoperative patient's information. In turn, it will possibly decrease the dissatisfactions rate in Sweden.

\section{Methods}

\section{Design}

We conducted a cross-sectional descriptive study including qualitative and quantitative data collection.

\section{Methods and analyses}

A study-specific questionnaire was distributed in paper form to all 65 TKA clinics in Sweden in May 2016. A list of all orthopaedic clinics performing TKA was obtained from the Swedish knee registry. A reminder letter was sent in October 2016 to increase the response rate. For each department, the questionnaire was sent to the orthopaedic surgeon locally responsible for registration of TKAs in the Swedish Knee Arthroplasty Register, who then distributed the questionnaire to all orthopaedic surgeons who performed TKA at that department. Knee departments in Sweden are located in either state-funded university hospitals, regional hospitals, small hospitals, or private clinics.

The initial response rate was $55 \%$, but the reminder letter increased this to $92 \%$ (60 clinics) (Appendix 1). The five orthopaedic clinics that failed to return the questionnaire were located in a university hospital $(n=1)$ and local hospitals $(n=4)$. Of the approximately 311 knee arthroplasty surgeons in Sweden, 219 answered the questionnaire. Thus, about $70 \%$ of the surgeons who regularly perform TKA surgery in Sweden answered the questionnaire. The reasons of $30 \%$ non-response were the surgeon's unwilling and uninterestingness according to orthopaedic chief managers. This rate was not related to the kind of hospital (University hospital, county council hospital or local hospital).

The sixteen-item questionnaire was designed by the researchers with the aim of investigating how information was given to and discussed with patients before surgery. The first fourteen questions covered written and oral information, patients' expectations, surgery on mild indication, and patients' psychiatric history. The choice of questions was based on evidence from the literature that these factors can have an impact on outcome $[4,9,12$, 13, 16, 19, 20, 32, 42-45]. A five-point Likert scale was used, with response alternatives of always, often, sometimes, seldom, and never after a discussion with a statistician (Appendix 2).

The final two questions were concerned with what the surgeons believed were the most common reasons for dissatisfaction after TKA, and were answered in the form of free text. These two questions were analysed qualitatively with a quantitative component. The text was coded inductively and grouped into five main categories based on 262 responses, and then analysed with a method based on thematic qualitative analysis [46, 47]. Initial coding was performed by the first author(AM). Then, the second author $(\mathrm{MH})$ checked the quality of the coding and changes were made until consensus was reached. To facilitate thematic analysis, responses on the two-free text items were uploaded into Version 11 of the NVivo software package (Boston, MA, USA).

There was no previous validated questionnaire which cover all the items that we intended to study. The questionnaire was written in Swedish by the major supervisor and the main researcher. The co-supervisor 
made then several changes on the language and the construct. It sent then to two independent orthopaedic surgeons to study the construct of the questionnaire. Further changes were made to the final version of the questionnaire. No comments have been received from the ethical board committee or knee orthopaedic surgeons if something in the questionnaire were ambiguous or not-understandable.

\section{Statistical analysis}

The statistical data analysis was divided into two parts:

1. General analysis: The data were described in terms of frequencies of answers. Duration of experience was not taken into consideration.

2. Specific analysis: The surgeons were divided into subgroups classified in terms of years of experience, volume of primary TKA/revision surgeries per year, and percentage of work done on knees. For statistical purposes, orthopaedic surgeons who performed $75 \%$ of their work on knees were grouped with those working solely on knees. Subgroup analysis was performed to see if there were differences between the groups (Table 1).

Data were analysed as frequencies of each answer (always, often, sometimes, seldom, and never). More specifically, subgroup data analysis was performed to see if there were any statistically significant differences (Table 1 ). The chi-square test was used to compare multiple categorical groups. Version 24 of the SPSS software package (IBM, SPSS Inc., Chicago, Illinois, USA) was used for the quantitative data analysis.

\section{Results}

\section{Descriptive statistics}

Only $8 \%$ of orthopaedic surgeons in Sweden worked solely on TKA surgery. In terms of experience, $43 \%$ had 5-15 years of experience in knee arthroplasty, 47\% performed 22-50 primary TKA procedures per year, and more than $50 \%$ performed revision arthroplasty of varying degrees of complexity (Table 1 ). The results are presented below in terms of the nine main questions. Those represented question 1,2,7,8,9,10,11,13 and 14. The answers of question 12 were presented together with question 13. Question 3,4,5 and 6 were dealt with knee surgeons experiences (Table 1, Appendix 2). The answer of question 15 and 16 were analysed qualitatively (Appendix 2).

\section{Written information}

The results showed that $58 \%$ of the knee surgeons always gave written information to their patients,
Table 1 Characteristics of Swedish knee surgeons $(N=219)$

\begin{tabular}{ll}
\hline Variable & $\begin{array}{l}\text { Orthopaedic knee surgeon } \\
(N=219)\end{array}$ \\
\hline Experience, $n$ (\%) & $32(15)$ \\
$\quad<5$ years & $95(43)$ \\
$5-15$ years & $80(37)$ \\
15-30 years & $11(5)$ \\
$>30$ years & $1(0.5)$ \\
Missing & \\
anee specialist, $n$ (\%) & $18(8)$ \\
$100 \%$ Knee specialist & $81(37)$ \\
$50 \%$ knee specialist & $120(55)$ \\
$25 \%$ Knee specialist & \\
Primary TKA/year, $n(\%)$ & $33(15)$ \\
$<22$ & $103(47)$ \\
$22-50$ & $54(25)$ \\
$50-100$ & $24(11)$ \\
$>100$ & $5(2)$ \\
Missing & \\
Revision TKA/year, $n$ (\%) & $2(1)$ \\
No revision & $58(45)$ \\
$>5$ revisions & $54(25)$ \\
Missing & $65(29)$ \\
\hline
\end{tabular}

The table shows the classification of knee surgeons according to the years of experience, the percentages of daily clinical work with knee joint, the volume of primary TKA performed by every surgeon per year and the volume of revision knee replacement surgery performed by every surgeon per year ${ }^{a}$ Percentage of daily clinical work with knee joint

while $18 \%$ never gave written information (Table 2). The highest percentages of written information were given by surgeons with more than 30 years of experience (64\%), who performed more than 100 primary TKA procedures per year $(71 \%)$, who performed more than 5 revisions per year $(60 \%)$, and who worked solely on knees (67\%). However, there was no statistically significant differences between the groups (Table 3).

Surgeons who said they never gave written information had the following characteristics: $15-30$ years of experience (23\%), performed fewer than 22 primary TKA procedures per year $(27 \%)$, did not perform any knee revisions (21\%), and spent $25 \%$ of their time as knee surgeons (23\%) (Table 4).

\section{Oral information}

Almost all knee surgeons informed their patients orally about the procedure. Oral information included indications, contraindications of surgery, benefits, risks, 
Table $\mathbf{2}$ Knee surgeons' measures regarding preoperative patient information

\begin{tabular}{ll}
\hline Variable & Orthopaedic knee \\
& surgeon \\
& $(N=219)$ \\
\hline
\end{tabular}

Written information, $n$ (\%)

$\begin{array}{ll}\text { Always } & 127(58) \\ \text { Often } & 24(11) \\ \text { Sometimes } & 7(3.2) \\ \text { Seldom } & 19(9) \\ \text { Never } & 40(18)\end{array}$

Oral information, $n(\%)$

Always

202 (92)

Often

Sometimes

$16(7)$

Seldom

$1(1)$

$0(0)$

Never

$0(0)$

Patient expectation, $n$ (\%)

Always

97 (44)

Often

78 (36)

Sometimes

Seldom

$32(15)$

$9(4)$

Never

$3(1)$

Dissatisfaction rate, $n(\%)$

Always

$91(42)$

Often

76 (35)

Sometimes

27 (12)

Seldom

15 (7)

Never

$9(4)$

Mild indications, $n$ (\%)

Always

$2(1)$

Often

Sometimes

$54(25)$

Seldom

98 (45)

Never

$52(24)$

Psychiatric consultation, $n$ (\%)

Always
Often
Sometimes
Seldom
Never
mpact of psychiatric disorder, $n$ (\%)
Always
Often
Sometimes
Seldom

38 (17)

38 (17)

119 (54)

34 (16)

$3(1)$
Table 2 Knee surgeons' measures regarding preoperative patient information (Continued)

\begin{tabular}{ll}
\hline Variable & $\begin{array}{l}\text { Orthopaedic knee } \\
\text { surgeon } \\
(N=219)\end{array}$ \\
\hline Never & $0(0)$ \\
Psychiatric history, $n(\%)$ & $42(19)$ \\
Always & $83(38)$ \\
Often & $59(27)$ \\
Sometimes & $28(13)$ \\
Seldom & $7(3)$ \\
Never & \\
Psychiatric questionnaire, $n(\%)$ & $213(97)$ \\
No & $2(1)$ \\
Yes & $3(1)$ \\
EQ-5D & $1(1)$ \\
HADS &
\end{tabular}

The table shows the numbers and percentages of all knee surgeons regarding the given preoperative patient's information

expected results, and prognosis. In terms of consistency, 92\% always informed their patients, $7 \%$ often informed their patients, and $1 \%$ sometimes informed their patients (Table 2).

Further classification of surgeons into subgroups did not show any statistically significant differences. The highest proportions of surgeons informing their patients orally were seen in surgeons with 15-30 years of experience (94\%), performing 22-50 primary TKA procedures per year (95\%), performing no revisions (94\%), and conducting $50 \%$ of their work on knees (95\%) (Table 3).

While experienced knee surgeons did not report the highest frequency of providing oral information, the percentage who did provide oral information was still high and there were no statistically significant differences between the groups. The lowest frequencies of giving oral information were in surgeons who "sometimes" informed patients verbally as follows: < 5 years of experience (3\%), 50-100 primary TKA procedures per year $(2 \%),<5$ revisions per year $(1 \%)$, and conducting $50 \%$ of their work on knees (1\%) (Table 4).

\section{Expectations}

There was an unequal distribution of orthopaedic surgeons asking about the patient's expectations: $44 \%$ always asked, 35\% often asked, 14\% sometimes asked, and the remaining $5 \%$ never or seldom asked (Table 2). 
Table 3 The sub groups of knee surgeons who gave the highest preoperative information $(N=219)$

\begin{tabular}{|c|c|c|c|c|c|c|c|c|}
\hline $\begin{array}{l}\text { Characteristics of } \\
\text { knee surgeons: }\end{array}$ & $\begin{array}{l}\text { Years of } \\
\text { experience }\end{array}$ & $P$-value ${ }^{*}$ & $\begin{array}{l}\text { TKA volume } \\
\text { per year }\end{array}$ & $P$-value ${ }^{*}$ & $\begin{array}{l}\text { Knee revision } \\
\text { per year }\end{array}$ & $P$-value ${ }^{*}$ & $\begin{array}{l}\text { Knee } \\
\text { specialist }\end{array}$ & $P$-value* \\
\hline \multicolumn{9}{|l|}{ Preoperative measures: } \\
\hline Written information & $>30$ & 0.72 & $>100$ & 0.25 & $>5$ & 0.31 & $100 \%$ & 0.24 \\
\hline Oral information & $15-30$ & 0.39 & $22-50$ & 0.50 & 0 & 0.33 & $50 \%$ & 0.32 \\
\hline Expectations & $>30$ & 0.22 & $>100$ & 0.51 & 0 & 0.19 & $50 \%$ & 0.08 \\
\hline Dissatisfaction rate & $>30$ & 0.69 & $>100$ & 0.17 & $<5$ & 0.47 & $50 \%$ & 0.79 \\
\hline Surgery on mild indication & $>30$ & 0.89 & $<22$ & 0.70 & $<5$ & 0.04 & $25 \%$ & 0.77 \\
\hline Psychiatric history & $<5$ & 0.09 & $>100$ & 0.59 & $<5$ & 0.70 & $50 \%$ & 0.94 \\
\hline Psychiatric consultation & $>30$ & 0.03 & $22-50$ & 0.07 & 0 & 0.31 & $25 \%$ & 0.07 \\
\hline Psychiatric impact & $<5$ & 0.14 & $22-50$ & 0.36 & 0 & 0.18 & $50 \%$ & 0.38 \\
\hline
\end{tabular}

The table shows the highest preoperative given information according to different groups of knee surgeons that were described in Table 1 ${ }^{*} \mathrm{Chi}{ }^{2}$ test

In terms of subgroups, $82 \%$ of surgeons with more than 30 years of experience, $54 \%$ of surgeons who performed more than 100 primary TKA procedures per year, $47 \%$ of surgeons who did not perform revisions, and $47 \%$ of surgeons who conducted $50 \%$ of their work on knees "always" asked about patient expectations. However, the differences again were not statistically significant (Table 3 ). The lowest results were among the following, who "never" asked about expectations: < 5 years of experience (3\%), 50-100 TKA procedures per year $(4 \%),<5$ revisions per year $(4 \%)$, and specialising $100 \%$ in knees (6\%) (Table 4$)$.

\section{Informing patients about the $20 \%$ dissatisfaction rate after TKA surgery}

Only $42 \%$ of surgeons always informed patients about the risk of dissatisfaction; 35\% often provided this information while approximately $10 \%$ never or seldom informed patients (Table 2). Surgeons who informed patients frequently had the following characteristics: > 30 years of experience (37\%), > 100 primary TKA procedures per year, $<5$ knee revisions per year $(52 \%)$, and conducting $50 \%$ of their work on knees (49\%) (Table 3). The lowest results were found among the following categories: < 5 years of experience (6\%), > 100 primary TKA procedures per year $(8 \%)$, no knee revisions (6\%), and specialising $100 \%$ in knees $(6 \%)$ (Table 4).

\section{Surgery on mild indications}

Only $24 \%$ of the surgeons never operated on mild indication, though an additional $45 \%$ seldom proceeded with surgery in these cases. However, the proportion of surgeons who sometimes, often, or always operated despite a suspicious indication was still high, at 31\% (Table 2).

Table 4 The sub groups of knee surgeons who gave the least preoperative information $(N=219)$

\begin{tabular}{|c|c|c|c|c|c|c|c|c|}
\hline $\begin{array}{l}\text { Characteristics of } \\
\text { knee surgeons: }\end{array}$ & $\begin{array}{l}\text { Years of } \\
\text { experience }\end{array}$ & $P$-value* & $\begin{array}{l}\text { TKA volume } \\
\text { per year }\end{array}$ & $P$-value ${ }^{*}$ & $\begin{array}{l}\text { Knee revisions } \\
\text { per year }\end{array}$ & $P$-value ${ }^{*}$ & $\begin{array}{l}\text { Knee } \\
\text { specialist }\end{array}$ & $P$-value* \\
\hline \multicolumn{9}{|l|}{ Preoperative measures: } \\
\hline Written information & $15-30$ & 0.72 & $<22$ & 0.25 & 0 & 0.31 & $25 \%$ & 0.24 \\
\hline Oral information & $<5$ & 0.39 & $50-100$ & 0.50 & $<5$ & 0.33 & $50 \%$ & 0.32 \\
\hline Expectations & $<5$ & 0.22 & $50-100$ & 0.51 & $<5$ & 0.19 & $100 \%$ & 0.08 \\
\hline Dissatisfaction rate & $<5$ & 0.69 & $>100$ & 0.17 & 0 & 0.47 & $100 \%$ & 0.79 \\
\hline Surgery on mild indication & $<5$ & 0.89 & $50-100$ & 0.70 & $<5$ & 0.04 & $50 \%$ & 0.77 \\
\hline Psychiatric history & $>30$ & 0.09 & $50-100$ & 0.59 & $>5$ & 0.70 & $100 \%$ & 0.94 \\
\hline Psychiatric consultation & $<5$ & 0.03 & 50-100 & 0.07 & 0 & 0.31 & $100 \%$ & 0.07 \\
\hline Psychiatric impact & $15-30$ & 0.14 & $>100$ & 0.36 & $>5$ & 0.18 & $50 \%$ & 0.38 \\
\hline
\end{tabular}

This table shows the lowest preoperative given information according to different groups of knee surgeons that were described in Table 1 ${ }^{*} \mathrm{Chi}{ }^{2}$-test 
The most appropriate answer on this issue is "seldom" [30, 45]. Orthopaedic surgeons who provided those answers had the following characteristics: $>30$ years of experience (55\%), < 22 TKA procedures per year (55\%), < 5 revisions per year $(57 \%, p=0.04)$, and conducting $25 \%$ of work on knees (45\%) (Table 3). Surgeons who gave the answer of "always" operating on mild indication had the following characteristics: < 5 years of experience, 50-100 primary TKA procedures per year $(4 \%),<5$ revisions per year $(2 \%)$ and conducting $50 \%$ of their work on knees (1\%) (Table 4 ).

\section{Psychiatric consultation}

Despite the known impact of psychiatric illness on TKA outcome, only one in ten of the surgeons always consulted a psychiatric unit; $17 \%$ did this often and a fifth did it sometimes (Table 2).

Stratifying the surgeons into four groups showed that surgeons who mostly answer "always" had the following criteria: > 30 years of experience $(18 \%, p=0.03)$, 22-50 primary TKA procedures per year (15\%), no revisions (12\%), and spending $25 \%$ of their time on knees (13\%). The only subgroup with a statistically significant difference was the group with more than 30 years of experience. Knee surgeons who never consulted a psychiatrist had the following characteristics: < 5 years of experience (25\%), 50-100 primary TKA procedures per year $(22 \%)$, no revisions (24\%), and specialising $100 \%$ in knees (Table 4).

\section{Impact of psychiatric problems on outcome}

A total of $29 \%$ of the surgeons believed that psychiatric problems always had a negative impact on outcome after TKA, 54\% believed there was often an impact, and $16 \%$ believed there was sometimes an impact. Although 2\% answered "rarely" to this question, there were no surgeons who answered "never" (Table 2).

The knee surgeons who believed that there was always a relationship had the following profile: $<5$ years of experience (41\%), 22-50 primary TKA procedures per year (34\%), no revisions (34\%), and conducting $50 \%$ of their work on knees (Table 3). Knee surgeons who believed that TKA outcome was seldom related to psychiatric problems had the following characteristics: $15-30$ years of experience (3\%), > 100 primary TKA procedures per year (4\%), > 5 revisions per year (3\%), and conducting $50 \%$ of their work on knees (Table 4).

\section{Psychiatric history}

Only a few of the surgeons used a psychiatric evaluation questionnaire (3\%) (Table 2), and only $20 \%$ always took a psychiatric history. Forty percent often took a psychiatric history, and $16 \%$ rarely or never used this kind of evaluation (Table 2).

Surgeons who always took a psychiatric history had the following characteristics: $<5$ years of experience $(28 \%),>100$ primary TKA procedures per year (25\%), < 5 revisions per year (26\%), and conducting $50 \%$ of their work on knees (22\%). The differences were not statistically significant (Table 3). Surgeons who never or seldom took a psychiatric history belonged to the following groups: > 30 years of experience (18\%), 50-100 primary TKA procedures per year $(20 \%),>5$ revisions per year (20\%), and specialising $100 \%$ in knees (17\%) (Table 4).

\section{Psychological or mechanical reasons for dissatisfaction}

One third of the surgeons believed that psychological factors were a reason for patient dissatisfaction, a quarter believed that mechanical factors played the biggest role, and another quarter believed that combinations of factors were behind this (Table 5).

\section{Thematic analysis: Reasons for dissatisfaction after knee surgery}

Five categories emerged in the thematic analysis, and are discussed below in descending order of their frequency of being mentioned.

\section{Patient expectations}

Almost half of the surgeons (122/262) stated that patients' expectations were a predictive factor of bad outcome. They described these expectations as too great, unrealistic, high, wrong, and unreasonable.

\section{Choice of patients to operate on}

The second most common reason for dissatisfaction was the choice of patients to operate on. A considerable number of surgeons (72/262) related bad outcome to patient selection. Their statements included mentions of bad preoperative physical and psychological

Table 5 TKA surgeon's opinion about the general cause of dissatisfaction $(N=219)$

\begin{tabular}{ll}
\hline Variables, $n(\%)$ & Surgeon's opinion \\
\hline Psychological/expectations & $66(30)$ \\
Mechanical/soft tissue & $56(26)$ \\
Combination & $59(27)$ \\
Unknown & $14(6)$ \\
Miscellaneous & $8(4)$ \\
Missing & $16(7)$
\end{tabular}

The table shows what knee surgeons thought in general as the main cause of patient's non-satisfaction after primary total knee arthroplasty 
plan, inadequate motivation for postoperative training, multiple previous surgeries, surgery in early stages of arthrosis, mild complaint, obesity, low pain threshold, anxiety, depression, wrong indication, co-morbidities, poor preoperative range of motion, and insufficient rehabilitation.

\section{Surgical factors}

The third factor was related to surgery. Many of the orthopaedic surgeons (41/262) mentioned surgeryrelated factors as a cause of dissatisfaction after TKA, including unskilled/inexperienced surgeon, insufficient surgical performance, mechanical issues, poor implant positioning, no implant better than the natural knee, scar tissue, instability, swelling, soft tissue envelope, ligament balance, and patella.

\section{Combination of factors}

A few of the surgeons (18/262) stated that poor outcome was determined by a combination of factors. This was the fourth common cause mentioned by the surgeons.

\section{Insufficient information}

The fifth and least commonly-mentioned factor that determined the poor outcome was patient information. Very few of the surgeons (9/262) mentioned this as an important factor, and none named it as a sole factor; it was mainly grouped with patient expectations.

\section{Discussion}

The Swedish orthopaedic surgeons in the present study described preoperative patient expectations as an important issue in predicting outcome after TKA surgery. However, this descriptive study revealed deficiencies among many TKA surgeons in supplying preoperative information. The discussion below aims to outline the extent of this problem among knee surgeons in Sweden.

All knee surgeons provided some kind of information to their patients preoperatively. However, only $58 \%$ of knee surgeons always provided written information, though $92 \%$ always informed their patients verbally. Preoperative information included information about indications, contraindications, surgical procedure, risks and benefits, outcome, and prognosis. Preoperative written and oral information has been shown to reduce postoperative pain and thereby enhance postoperative outcome [40, 41, 48], and a qualitative study on TKA patients showed that patients who were well informed preoperatively trusted their health care providers [40]. However, an earlier study showed that preoperative information about anatomy and patho-anatomy had a limited effect on pain management, while information about pain was more effective [42]. Furthermore, it is of utmost importance that the patients understand the information given. A recent study found that patients with low health literacy had impaired postoperative recovery and lower postoperative quality of life [49].

Written information in the form of booklets has been shown to have a positive effect on outcome after TKA [48]. Another study pointed out the importance of providing both verbal and written information together in order to facilitate postoperative pain control [41]. Consequently, the preoperative provision of written information to all TKA patients could offer a way to increase the satisfaction rate.

In terms of asking about patients' expectations, only $44 \%$ of the surgeons always discussed this important issue with their patients. An earlier study showed that TKA surgery failed to meet the patients' expectations when it came to kneeling, squatting, and stair climbing, and in particular that the fulfilment of expectations was highly correlated with satisfaction [43]. Tilbury et al. came to a similar conclusion, emphasizing the importance of preoperative information and education due to the substantial number of TKA patients with unfulfilled expectations [44]. It is very important for the surgeon to ask about the patient's expectations, and make it clear to them which activities might be difficult to perform after the surgery. A study revealed that only young, strong patients who did not have a problem with ascending or descending stairs preoperatively were likely to be able to use stairs postoperatively without a problem [32]. Expectations of improvement in this functional ability may thus contribute to patients' feeling disappointed after surgery, and so impelling knee surgeons to ask their patients about expectations may decrease the rate of dissatisfaction due to unfulfilled expectations. $\mathrm{Pa}$ tient's expectations on the outcome of the TKA are not only based on the information given by the knee surgeons, but rather from discussions with other people like friends, family and from information in media [50].

It is not known whether information about dissatisfaction rate affects outcome after TKA. Earlier research revealed that up to $20 \%$ of TKA patients were disappointed with their results $[3,4,19,22]$.We therefore suggest that informing patients about the dissatisfaction rate before surgery is of importance, as it could increase their awareness of the expected success rate. Further research is needed to create an individualized risk prediction's tool. 
Only $42 \%$ of surgeons in our study always discussed the success rate after TKA surgery, and 10\% never discussed this with their patients. Previous studies have shown that the severity of osteoarthritis correlates with satisfaction rate. Schnurr et al. found that patients suffering from mild or moderate osteoarthritis were at risk of dissatisfaction after TKA, and recommended that patients should be told about this [45]. Another study showed a similarly high dissatisfaction rate among people with mild osteoarthritis changes, and also revealed a high prevalence of chronic non-orthopaedic conditions among these patients, including anxiety/depression, fibromyalgia, low back pain, and prior brain injury [13].

Our Swedish data showed a high percentage (31\%; $68 / 219)$ of knee surgeons who sometimes, often or always operated on painful knees with mild radiological osteoarthritis in patients with anxiety/depression. Previous medical history is fundamental in preoperative evaluation. Nonetheless, medical and psychiatric illnesses are equally important, and should always be included in preoperative judgment. In recent years, there has been more recognition of the impact of psychological factors on joint prosthesis outcome. Many studies show a negative relationship between depression/anxiety and prosthesis outcome $[3,4,6,9,12,13,16,17]$. However, only $20 \%$ of the surgeons in our study always took a psychiatric history, and $10 \%$ never or rarely enquired about psychiatric problems. Earlier research has shown that the rate of depression is $10-13 \%$ among the arthroplasty population, and that depression is correlated with an increased risk of poor outcome after surgery $[8,9]$. Thus, awareness of this patient category needs to be increased, at least among Swedish knee surgeons.

Many studies recommend preoperative evaluation and management of psychiatric problems to mitigate postoperative complaints, thereby decreasing dissatisfaction rate after TKA $[3,8,11,15,17,18$, $24,51,52]$. In our survey, only $10 \%$ of orthopaedic surgeons always consulted a psychiatrist when they suspected a psychiatric problem, and $16 \%$ never or rarely did this. Moreover, only $3 \%$ of the surgeons used preoperative psychiatric questionnaires. With the support of the above-mentioned literature, the use of this kind of questionnaire can detect patients with a psychiatric disorder. There are no systematic protocols yet in Sweden to refer patients with psychiatric diseases for a professional psychiatric evaluation before TKA surgery. We recommend to build up such systems which we consider as important as referral for physical evaluation before surgery.
The knee surgeon's responses were consistent with literature considering their believes about the causes of dissatisfaction. This was regarded patients' expectations $[12,20,32,43,44,53]$, the choice of patient to operate on $[3,7,13,15,18,45,52,54-56]$, surgery related factors $[21,57,58]$, combination of factors [10] and poor provision of information [12, 40, 44, 48, 59].

One limitation of this study is its descriptive design; However, the study does reveal the extent of the knee surgeons who do not provide a sufficient preoperative patient information in Sweden, which may be similar in other countries. Descriptive studies are ranked low in the hierarchy of evidence [60], but the strength of this survey is that it is unique in describing for the first time Swedish knee surgeons' attitude to preoperative information. In addition, the qualitative analysis of surgeons' beliefs shows how surgeons think about dissatisfaction after TKA patients in Sweden. Another weakness is the absence of psychometric analysis of the questionnaire. The questionnaire was constructed by the researchers with the aim of investigating the attitudes of knee surgeons, as there was no validated questionnaire which could answer the aim of the study. Many differences between the groups were statistically non-significant because of multi-categorical comparison between the groups. When we condensed these categories, the differences became statistically significant, however without clinical importance. The high response rate added more strength to this study.

Another limitation of the study is that it only evaluated frequency of information provision, which does not tell us anything about the quality of this information, which may also be important and influence patients' expectations and satisfaction [35, 40$42,48,59,61]$. Moreover, the surgeon's believes and attitude that showed by the study may not represent the actual daily behavior of knee surgeons.

\section{Conclusions}

The findings in this survey show that Swedish knee surgeons are aware of factors which predict poor outcome after knee arthroplasty surgery, and that they take these factors into consideration when verbally informing patients preoperatively. On the other hand, more effort is needed in improving written information, analysis of preoperative patient expectations, taking a psychiatric history, consulting a psychiatrist, and not operating on mild indications. Many studies support the negative effect of these factors on outcome. Changing the attitudes of knee surgeons towards preoperative care might decrease dissatisfaction rate. This survey may serve as background for future research regarding preoperative patient selection, surgeon attitudes, and satisfaction rate. 


\section{Appendix 1}

Table 6 Swedish hospitals which participated in the survey. SPSS statistical program

\begin{tabular}{|c|c|c|c|c|}
\hline No. & Hospital & Knee surgeons (total no.) & percent & Knee surgeons (answered) \\
\hline 1. & Akademiska Uppsala & 8 & 2.8 & 2 \\
\hline 2. & Aleris Motala & 4 & 1.4 & 3 \\
\hline 3. & Alingsås & 5 & 1.7 & 4 \\
\hline 4. & Blekinge & 7 & 2.4 & 7 \\
\hline 5. & Bollnäs & 3 & 1.0 & 2 \\
\hline 6. & Capio Movement/Halms. & 5 & 1.7 & 2 \\
\hline 7. & Carlanderska & 2 & 0.7 & 2 \\
\hline 8. & Danderyd & 6 & 2.1 & 6 \\
\hline 9. & Eksjö-Nässjö-Högla & 4 & 1.4 & 4 \\
\hline 10. & Elisabeth/Uppsala & 1 & 0.3 & 1 \\
\hline 11. & Enköping & 6 & 2.1 & 6 \\
\hline 12. & Falun & 6 & 2.1 & 2 \\
\hline 13. & Gävle & 6 & 2.1 & 6 \\
\hline 14. & Halmstad & 7 & 2.4 & 3 \\
\hline 15. & Helsingborg & 5 & 1.7 & 1 \\
\hline 16. & Huddinge & 7 & 2.4 & 1 \\
\hline 17. & Hudiksvall & 3 & 1.0 & 1 \\
\hline 18. & Hässleholm & 3 & 1.0 & 2 \\
\hline 19. & Kalmar & 3 & 1.0 & 3 \\
\hline 20. & Karlskoga & 5 & 1.7 & 5 \\
\hline 21. & Karlstad & 5 & 1.7 & 3 \\
\hline 22. & Karolinska /Solna & 4 & 1.4 & 4 \\
\hline 23. & Kungsälv & 4 & 1.4 & 4 \\
\hline 24. & Lidköping & 5 & 1.7 & 3 \\
\hline 25. & Lindesberg & 6 & 2.1 & 6 \\
\hline 26. & Ljungby & 5 & 1.7 & 3 \\
\hline 27. & Lycksele & 2 & 0.7 & 2 \\
\hline 28. & Mora & 6 & 2.1 & 1 \\
\hline 29. & Mälar/Eskilstuna & 8 & 2.8 & 7 \\
\hline 30. & Nacka Aleris & 3 & 1,0 & 3 \\
\hline 31. & Norrtälje & 3 & 1.0 & 3 \\
\hline 32. & Nyköping & 4 & 1.4 & 2 \\
\hline 33. & Orthocenter/Göteborg & 3 & 1.0 & 3 \\
\hline 34. & Orthocenter/Löwenstr & 4 & 1.4 & 4 \\
\hline 35. & Ortopediska huset & 4 & 1.4 & 3 \\
\hline 36. & Oskarshamn & 3 & 1.0 & 3 \\
\hline 37. & Piteå/Sunderby & 6 & 2.1 & 5 \\
\hline 38. & Ryhov/Jönköping & 3 & 1.0 & 1 \\
\hline 39. & Sahlgrenska/Mölndal & 12 & 4.2 & 10 \\
\hline 40. & Skellefteå & 4 & 1.4 & 4 \\
\hline 41. & Skene/Södra Älvsborgs & 5 & 1.7 & 5 \\
\hline 42. & Skövde & 3 & 1.0 & 3 \\
\hline 43. & Sollefteå & 2 & 0.7 & 2 \\
\hline
\end{tabular}


Table 6 Swedish hospitals which participated in the survey. SPSS statistical program (Continued)

\begin{tabular}{|c|c|c|c|c|}
\hline No. & Hospital & Knee surgeons (total no.) & percent & Knee surgeons (answered) \\
\hline 44. & St. Görans & 4 & 1.4 & 4 \\
\hline 45. & Sundsvall & 2 & 0.7 & 2 \\
\hline 46. & SUS(Lund/Malmö) & 16 & 5.6 & 10 \\
\hline 47. & Södertälje & 5 & 1.7 & 5 \\
\hline 48. & Södersjukhuset & 9 & 3.1 & 8 \\
\hline 49. & Torsby & 4 & 1.4 & 2 \\
\hline 50. & Uddevalla & 5 & 1.7 & 2 \\
\hline 51. & USÖ/Örebro & 3 & 1.0 & 3 \\
\hline 52. & Varberg & 5 & 1.7 & 5 \\
\hline 53. & Vrinnevis/Norrköping & 4 & 1.4 & 4 \\
\hline 54. & Värnamo & 4 & 1.4 & 4 \\
\hline 55. & Västervik & 3 & 1.0 & 3 \\
\hline 56. & Västerås & 5 & 1.7 & 2 \\
\hline 57. & Växjö & 7 & 2.4 & 7 \\
\hline 58. & Ängelholm & 3 & 1.0 & 3 \\
\hline 59. & Örnsköldsvik & 3 & 1.0 & 3 \\
\hline \multirow[t]{2}{*}{60.} & Östersund & 5 & 1.7 & 5 \\
\hline & & 287 & 100 & 219 \\
\hline
\end{tabular}

The table shows the numbers and names of participating hospitals. It shows also the total number of knee surgeons who are working in each hospital and the number of knee surgeons who participated in the survey

\section{Appendix 2}

Table 7 The questions answered by knee surgeons in the survey

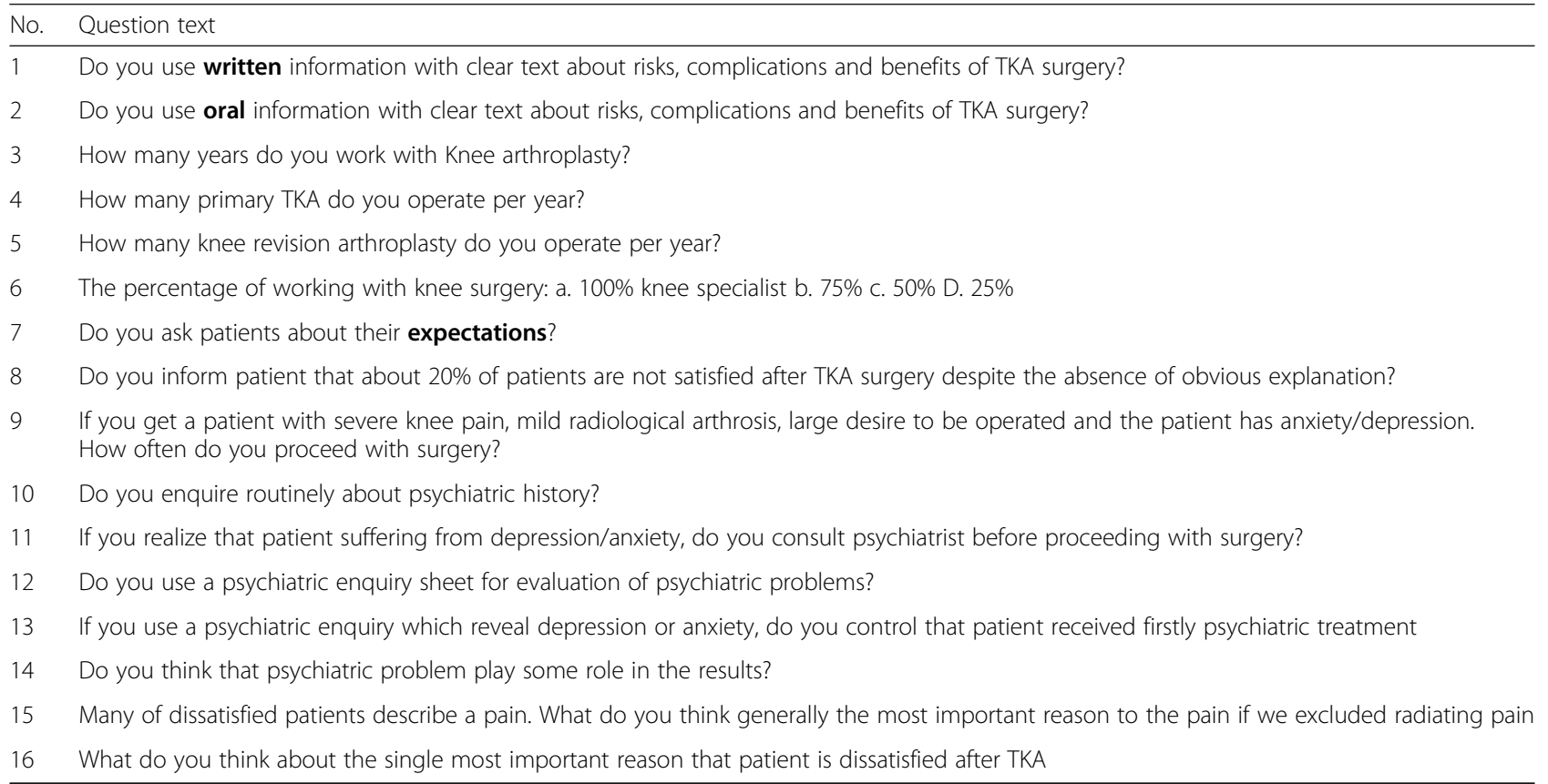




\section{Abbreviations}

SPSS: Statistical Package for the Social Sciences; TKA: Total knee arthroplasty

\section{Acknowledgements}

We wish to thank Ole Brus Clinical Epidemiology and Biostatistics, School of Medical Sciences, Örebro University, Örebro, Sweden) for statistical advice and help with the SPSS software package. We are also grateful to all the surgeons who answered the study questionnaire.

\section{Funding}

This study was funded by the Örebro Research Committee, Sweden, and the Orthopaedic Department, Karlskoga Hospital, Sweden. No external funding or benefits were received. The funders had no role in the design and conduct of the study; collection, management, analysis, and interpretation of the data; preparation, review, or approval of the manuscript; and decision to submit the manuscript for publication.

\section{Availability of data and materials}

The datasets used and/or analysed during the current study are available from the corresponding author on reasonable request.

\section{Authors' contributions}

AM created the study protocol and design, collected the data, performed the analysis, and wrote the manuscript. MHN and PW contributed to the study design, the analysis, and revision of the manuscript. All authors read and approved the final manuscript.

\section{Ethics approval and consent to participate}

The collected data do not include patient identity. However, a written information and consent was sent together with the questionnaire to every participant. Participant's name and personal information were not requested. Ethical approval was obtained from the Regional Ethics Committee in Uppsala Sweden (reference number 2016/191)

\section{Consent for publication}

Not applicable.

\section{Competing interests}

The authors declare that they have no competing interests.

\section{Publisher's Note}

Springer Nature remains neutral with regard to jurisdictional claims in published maps and institutional affiliations.

\section{Author details}

${ }^{1}$ Department of Orthopaedics, Örebro County, Sweden. ${ }^{2}$ Faculty of Medicine and Health, School of Medical Sciences, Örebro University, Örebro, Sweden. ${ }^{3}$ Faculty of Medicine and Health, School of Health Sciences, Örebro University, Örebro, Sweden.

Received: 24 June 2018 Accepted: 15 November 2018

Published online: 24 November 2018

\section{References}

1. Kurtz S, Ong K, Lau E, Mowat F, Halpern M. Projections of primary and revision hip and knee arthroplasty in the United States from 2005 to 2030. J Bone Joint Surg Am. 2007;89(4):780-5.

2. Skar: the swedish knee arthroplasty register - Annu Rep 2016 - PART I. In. vol. 2016, 2016 edn: The swedish knee arthroplasty register - Annu Rep 2016 - Part l; 2016: 15

3. Ali A, Lindstrand A, Sundberg M, Flivik G. Preoperative anxiety and depression correlate with dissatisfaction after Total knee arthroplasty: a prospective longitudinal cohort study of 186 patients, with 4-year follow-up. J Arthroplast. 2017;32(3):767-70

4. Ayers DC, Franklin PD, Trief PM, Ploutz-Snyder R, Freund D. Psychological attributes of preoperative total joint replacement patients: implications for optimal physical outcome. J Arthroplasty. 2004;19(7 Suppl 2):125-30.

5. Berger RA, Crossett LS, Jacobs JJ, Rubash HE. Malrotation causing patellofemoral complications after total knee arthroplasty. Clin Orthop Relat Res. 1998;356:144-53.
6. Bletterman AN, de Geest-Vrolijk ME, Vriezekolk JE, Nijhuis-van der Sanden MW, van Meeteren NL, Hoogeboom TJ. Preoperative psychosocial factors predicting patient's functional recovery after total knee or total hip arthroplasty: a systematic review. Clin Rehabil. 2017;32(4):512-25.

7. Bozic KJ, Lau E, Ong K, Chan V, Kurtz S, Vail TP, Rubash HE, Berry DJ. Risk factors for early revision after primary TKA in Medicare patients. Clin Orthop Relat Res. 2014;472(1):232-7.

8. Browne JA, Sandberg BF, D'Apuzzo MR, Novicoff WM. Depression is associated with early postoperative outcomes following total joint arthroplasty: a nationwide database study. J Arthroplast. 2014;29(3):481-3.

9. Gandhi R, Zywiel MG, Mahomed NN, Perruccio AV: Depression and the overall burden of painful joints: an examination among individuals undergoing hip and knee replacement for osteoarthritis. Arthritis 2015, 2015:327161.

10. Gibon E, Goodman MJ, Goodman SB. Patient satisfaction after Total knee arthroplasty: A Realistic or Imaginary Goal? Orthop Clin North Am. 2017; 48(4):421-31.

11. Gold HT, Slover JD, Joo L, Bosco J, lorio R, Oh C. Association of Depression with 90-day hospital readmission after Total joint arthroplasty. J Arthroplast. 2016;31(11):2385-8.

12. Greene KA, Harwin SF. Maximizing patient satisfaction and functional results after total knee arthroplasty. J Knee Surg. 2011;24(1):19-24.

13. Jacobs CA, Christensen CP, Karthikeyan T. Chronic non-orthopedic conditions more common in patients with less severe degenerative changes that have elected to undergo Total knee arthroplasty. J Arthroplast. 2015;30(7):1146-9.

14. Jeffery RS, Morris RW, Denham RA. Coronal alignment after total knee replacement. J Bone Joint Surg Br. 1991;73(5):709-14.

15. Judge A, Arden NK, Cooper C, Kassim Javaid M, Carr AJ, Field RE, Dieppe PA Predictors of outcomes of total knee replacement surgery. Rheumatology (Oxford). 2012;51(10):1804-13.

16. Khatib Y, Madan A, Naylor JM, Harris IA. Do psychological factors predict poor outcome in patients undergoing TKA? A systematic review. Clin Orthop Relat Res. 2015:473(8):2630-8.

17. Klement MR, Nickel BT, Penrose CT, Bala A, Green CL, Wellman SS, Bolognesi MP, Seyler TM. Psychiatric disorders increase complication rate after primary total knee arthroplasty. Knee. 2016;23(5):883-6.

18. Lingard EA, Katz JN, Wright EA, Sledge CB: Predicting the outcome of total knee arthroplasty. J Bone Joint Surg Am 2004, 86-a(10):2179-2186.

19. Lostak J, Gallo J, Zapletalova J. Patient satisfaction after Total knee arthroplasty. Analysis of pre-operative and Peri-operative parameters influencing results in 826 patients. Acta Chir Orthop Traumatol Cechoslov. 2016;83(2):94-101.

20. Nilsdotter AK, Toksvig-Larsen S, Roos EM. Knee arthroplasty: are patients' expectations fulfilled? A prospective study of pain and function in 102 patients with 5-year follow-up. Acta Orthop. 2009;80(1):55-61.

21. Norton EC, Garfinkel SA, McQuay LJ, Heck DA, Wright JG, Dittus R, Lubitz RM. The effect of hospital volume on the in-hospital complication rate in knee replacement patients. Health Serv Res. 1998;33(5 Pt 1):1191-210.

22. Robertsson O, Dunbar M, Pehrsson T, Knutson K, Lidgren L. Patient satisfaction after knee arthroplasty: a report on 27,372 knees operated on between 1981 and 1995 in Sweden. Acta Orthop Scand. 2000;71(3):262-7.

23. Robertsson O, Dunbar MJ. Patient satisfaction compared with general health and disease-specific questionnaires in knee arthroplasty patients. J Arthroplast. 2001:16(4):476-82.

24. Santaguida PL, Hawker GA, Hudak PL, Glazier R, Mahomed NN, Kreder HJ, Coyte PC, Wright JG. Patient characteristics affecting the prognosis of total hip and knee joint arthroplasty: a systematic review. Can J Surg. 2008;51(6): 428-36.

25. Ali A, Sundberg M, Robertsson O, Dahlberg LE, Thorstensson CA, RedlundJohnell I, Kristiansson I, Lindstrand A. Dissatisfied patients after total knee arthroplasty: a registry study involving 114 patients with 8-13 years of followup. Acta Orthop. 2014;85(3):229-33.

26. Clement ND, Bardgett M, Weir D, Holland J, Deehan DJ. Increased symptoms of stiffness 1 year after total knee arthroplasty are associated with a worse functional outcome and lower rate of patient satisfaction. Knee Surg Sports Traumatol Arthrosc. 2018. Online ISSN1433-7347.

27. Dailiana ZH, Papakostidou I, Varitimidis S, Liaropoulos L, Zintzaras E, Karachalios T, Michelinakis E, Malizos KN. Patient-reported quality of life after primary major joint arthroplasty: a prospective comparison of hip and knee arthroplasty. BMC Musculoskelet Disord. 2015;16:366. 
28. Kievit AJ, van Geenen RC, Kuijer PP, Pahlplatz TM, Blankevoort L, Schafroth MU. Total knee arthroplasty and the unforeseen impact on return to work: a cross-sectional multicenter survey. J Arthroplast. 2014;29(6):1163-8.

29. Van Onsem S, Verstraete M, Dhont S, Zwaenepoel B, Van Der Straeten C, Victor J. Improved walking distance and range of motion predict patient satisfaction after TKA. Knee Surg Sports Traumatol Arthrosc. 2018.

30. Verra WC, Witteveen KQ, Maier AB, Gademan MG, van der Linden HM, Nelissen RG. The reason why orthopaedic surgeons perform total knee replacement: results of a randomised study using case vignettes. Knee Surg Sports Traumatol Arthrosc. 2016;24(8):2697-703.

31. Weinberg DB, Gittell JH, Lusenhop RW, Kautz CM, Wright J. Beyond our walls: impact of patient and provider coordination across the continuum on outcomes for surgical patients. Health Serv Res. 2007;42(1 Pt 1):7-24.

32. Zeni JA Jr, Snyder-Mackler L. Preoperative predictors of persistent impairments during stair ascent and descent after total knee arthroplasty. J Bone Joint Surg Am. 2010;92(5):1130-6.

33. Bethge M, Kohler L, Kiel J, Thren K, Gutenbrunner C. Sports activity following joint arthroplasty: experiences and expectations of elderly patients--findings from a qualitative content analysis of guided interviews. Rehabilitation (Stuttg). 2015;54(4):233-9.

34. Brander VA, Stulberg SD, Adams AD, Harden RN, Bruehl S, Stanos SP, Houle T. Predicting total knee replacement pain: a prospective, observational study. Clin Orthop Relat Res. 2003;416:27-36.

35. Clement ND, Bardgett M, Weir D, Holland J, Gerrand C, Deehan DJ. The rate and predictors of patient satisfaction after total knee arthroplasty are influenced by the focus of the question. Bone Joint J. 2018;100-b(6):740-8.

36. Clode NJ, Perry MA, Wulff L. Does physiotherapy prehabilitation improve pre-surgical outcomes and influence patient expectations prior to knee and hip joint arthroplasty? Int J Orthop Trauma Nurs. 2018;30:14-9.

37. Filbay SR, Judge A, Delmestri A, Arden NK: Evaluating Patients' expectations from a novel patient-centered perspective predicts knee arthroplasty outcome. J Arthroplast 2018, 33(7):2146-2152.e2144.

38. Indications for Total Knee Arthroplasty and Choice of Prosthesis [http://www.med.or.jp/english/pdf/2001_04/153_158.pdf].

39. Harris IA, Harris AM, Naylor JM, Adie S, Mittal R, Dao AT. Discordance between patient and surgeon satisfaction after total joint arthroplasty. J Arthroplast. 2013;28(5):722-7.

40. Conradsen S, Gjerseth MM, Kvangarsnes M. Patients' experiences from an education programme ahead of orthopaedic surgery - a qualitative study. J Clin Nurs. 2016;25(19-20):2798-806.

41. Andersson V, Otterstrom-Rydberg E, Karlsson AK. The importance of written and verbal information on pain treatment for patients undergoing surgical interventions. Pain Manag Nurs. 2015;16(5):634-41.

42. Louw A, Diener I, Butler DS, Puentedura EJ. Preoperative education addressing postoperative pain in total joint arthroplasty: review of content and educational delivery methods. Physiother Theory Pract. 2013;29(3):175-94.

43. Scott CE, Bugler KE, Clement ND, MacDonald D, Howie CR, Biant LC. Patient expectations of arthroplasty of the hip and knee. J Bone Joint Surg Br. 2012; 94(7):974-81.

44. Tilbury C, Haanstra TM, Leichtenberg CS, Verdegaal SH, Ostelo RW, de Vet HC, Nelissen RG, Vliet Vlieland TP. Unfulfilled expectations after Total hip and knee arthroplasty surgery: there is a need for better preoperative patient information and education. J Arthroplast. 2016:31(10):2139-45.

45. Schnurr C, Jarrous M, Gudden I, Eysel P, Konig DP. Pre-operative arthritis severity as a predictor for total knee arthroplasty patients' satisfaction. Int Orthop. 2013;37(7):1257-61.

46. Boyatzis RE. Transforming qualitative information, thematic analysis and code development, vol. 1. London, New Delhi: International educational and profissional publisher, thousands oaks; 1998

47. Braun V, Clarke V. What can "thematic analysis" offer health and wellbeing researchers? Int J Qual Stud Health Well-being. 2014;9:26152.

48. Eschalier B, Descamps S, Pereira B, Vaillant-Roussel H, Girard G, Boisgard S, Coudeyre E. Randomized blinded trial of standardized written patient information before total knee arthroplasty. PLoS One. 2017;12(7):e0178358.

49. Halleberg Nyman M, Nilsson U, Dahlberg K, Jaensson M. Association between functional health literacy and postoperative recovery, health care contacts, and health-related quality of life among patients undergoing day surgery: secondary analysis of a randomized clinical trial. JAMA Surg. 2018.

50. Meneghini RM, Russo GS, Lieberman JR. Modern perceptions and expectations regarding total knee arthroplasty. J Knee Surg. 2014;27(2):93-7.
51. Rasouli MR, Menendez ME, Sayadipour A, Purtill JJ, Parvizi J. Direct cost and complications associated with Total joint arthroplasty in patients with preoperative anxiety and depression. J Arthroplast. 2016;31(2):533-6.

52. Schwartz FH, Lange J. Factors that affect outcome following Total joint arthroplasty: a review of the recent literature. Curr Rev Musculoskelet Med. 2017.

53. Dowsey MM, Scott A, Nelson EA, Li J, Sundararajan V, Nikpour M, Choong PF. Using discrete choice experiments as a decision aid in total knee arthroplasty: study protocol for a randomised controlled trial. Trials. 2016; 17(1):416.

54. Pagnotta G, Rich E, Eckardt P, Lavin P, Burriesci R. The effect of a rapid rehabilitation program on patients undergoing unilateral Total knee arthroplasty. Orthop Nurs. 2017;36(2):112-21.

55. Fernandes L, Roos EM, Overgaard S, Villadsen A, Sogaard R. Supervised neuromuscular exercise prior to hip and knee replacement: 12-month clinical effect and cost-utility analysis alongside a randomised controlled trial. BMC Musculoskelet Disord. 2017;18(1):5.

56. Vavro M, Ziakova E, Gazdikova K, Farkasova D. Does standard post-operative rehabilitation have its place after total knee replacement? Bratisl Lek Listy. 2016;117(10):605-8.

57. Liddle AD, Pandit $H$, Judge A, Murray DW. Effect of surgical caseload on revision rate following Total and Unicompartmental knee replacement. J Bone Joint Surg Am. 2016:98(1):1-8.

58. Wilson S, Marx RG, Pan TJ, Lyman S. Meaningful thresholds for the volumeoutcome relationship in Total knee arthroplasty. J Bone Joint Surg Am. 2016;98(20):1683-90

59. Majid N, Lee S, Plummer V. The effectiveness of orthopedic patient education in improving patient outcomes: a systematic review protocol. JBI Database System Rev Implement Rep. 2015;13(1):122-33.

60. Institute tJB: New JBI Levels of Evidence. 2013:1-6.

61. Goldsmith L, Suryaprakash N, Randall E, Shum J, MacDonald V, Sawatzky R, Hejazi S, Davis JC, McAllister P, Bryan S. The importance of informational, clinical and personal support in patient experience with total knee replacement: a qualitative investigation. BMC Musculoskelet Disord. 2017; 18(1):127

\section{Ready to submit your research? Choose BMC and benefit from:}

- fast, convenient online submission

- thorough peer review by experienced researchers in your field

- rapid publication on acceptance

- support for research data, including large and complex data types

- gold Open Access which fosters wider collaboration and increased citations

- maximum visibility for your research: over $100 \mathrm{M}$ website views per year

At $\mathrm{BMC}$, research is always in progress.

Learn more biomedcentral.com/submission 